\title{
Pelapisan Thermal Barrier Coating (TBC) NiAl pada Paduan Logam Berbasis Co
}

\author{
Toto Sudiro, ${ }^{*}$ Anggito P. Tetuko, Kusnandar, Hubby 'Izuddin, dan K.A.Z. Thosin \\ Pusat Penelitian Fisika,Lembaga Ilmu Pengetahuan Indonesia (LIPI) \\ Kawasan PUSPIPTEK Serpong, Tangerang 15310
}

\begin{abstract}
Intisari
Sistem pelapisan material untuk aplikasi temperatur tinggi yang dikenal dengan Thermal Barrier Coating (TBC) telah banyak diaplikasikan pada komponen mesin produksi energi. Sistem ini terdiri atas 4 lapisan: substrat, bondcoat, TGO dan keramik topcoat. Penambahan unsur penguat batas butiran berfungsi untuk meningkatkan ketahanan material terhadap erosi, korosi dan oksidasi sehingga dapat memperpanjang umur pemakaian dan mengurangi biaya operasional. Pada makalah ini akan dibahas pengembangan pelapisan TBC NiAl pada paduan logam berbasis kobalt Co dengan penambahan unsur penguat batas butir menggunakan gabungan metoda Electro-platting dan Pack-cementation. Hasil pelapisan sebelum dan sesudah tes oksidasi dianalisa dengan SEM, XRD dan EPMA.
\end{abstract}

KATA KUNCI: Thermal barrier coating, electro-plating, pack-cementation, kobalt

\section{PENDAHULUAN}

Penelitian dan pengembangan pada mesin produksi energi seperti halnya turbin gas terus dilakukan dalam upaya meningkatkan efisiensi termalnya. Salah satu cara untuk meningkatkan efisiensi turbin gas dengan cara meningkatkan temperatur gas masuk yang digunakan sebagai media penggerak sudu-sudu turbin dan mengurangi penggunaan udara pendingin [1]. Dengan adanya peningkatan efisiensi termal berarti dapat mengurangi konsumsi bahan bakar dan juga dapat mengurangi emisi gas ke lingkungan (green-house effect).

Peningkatan temperatur kerja turbin gas harus diiringi dengan perbaikan struktur material yang digunakan pada mesin turbin tersebut. Tidak hanya tahan terhadap pembebanan mekanik tetapi juga tahan terhadap erosi, korosi dan oksidasi temperatur tinggi $\left(<1100^{\circ} \mathrm{C}\right)$, sehingga dapat memperpanjang umur pemakaian dan mengurangi biaya operasional turbin gas. Perbaikan ini dapat dilakukan dengan cara melindungi atau melapisi substrat dengan suatu barier yang dikenal dengan sistem thermal barrier coating (TBC). Sistem ini telah diaplikasikan untuk melindungi substrat yang berupa paduan logam berbasis nikel Ni dan kobalt Co pada aplikasi komponen mesin turbin gas [2].

Hingga saat ini, ada dua jenis teknologi komersial yang digunakan untuk mendeposisikan sistem TBC pada substrat, yaitu Air plasma spray coating (APS) dan Electron beam physical vapor deposition (EBPVD) [3]. Namun demikian, kedua teknologi ini masih terbilang mahal untuk diaplikasikan di Indonesia. Oleh karena itu, perlu dikembangkan suatu penelitian dengan teknologi yang lebih murah, sederhana dan memungkinkan untuk diaplikasikan di Indonesia. Mengingat hingga saat ini, ketergantungan pihak industri di Indonesia ter-

*E-MAIL: toto.sudirodlipi.go.id hadap pelayanan jasa asing sangatlah besar.

\section{DASAR TEORI}

Sistem TBC, yang digunakan untuk melapisi dan melindungi komponen mesin turbin gas terdiri atas 4 lapisan [4], yaitu: (i). substrat, berupa paduan logam berbasis nikel Ni dan kobalt Co, (ii). bondcoat, lapisan tahan oksidasi yang berupa MCrAlY ( $\mathrm{M}=\mathrm{Ni}, \mathrm{Co}$ atau $\mathrm{Fe}$ ) atau aluminide (NiAl atau Ni2Al3) $(\approx 100 \mu \mathrm{m})$, lapisan ini berfungsi sebagai pelindung substrat dari oksidasi dan korosi temperatur tinggi serta meminimumkan perbedaan koefisien termal ekspansi (CTE) antara substrat dan lapisan topcoat, (iii). thermal grow oxide (TGO), berupa $\mathrm{Al}_{2} \mathrm{O}_{3}$ atau $\mathrm{Cr}_{2} \mathrm{O}_{3}(1-10 \mu \mathrm{m})$ yang terbentuk dari hasil oksidasi bondcoat dan bersifat protektif serta berfungsi sebagai perekat antara bondcoat-topcoat, dan (iv). keramik topcoat, berupa $7 \mathrm{wt} \% \mathrm{Y}_{2} \mathrm{O}_{3}$-stabilized $\mathrm{ZrO}_{2}(100-400 \mathrm{~m})$ yang mempunyai titik leleh tinggi, konduktivitas termal rendah, koefisien termal ekspansi yang linear, serta tahan terhadap korosi, erosi dan oksidasi (Gambar 1.). Dengan dikembangkannya sistem ini, dapat mengurangi perbedaan temperatur antara permukaan dan substrat hingga $100-300^{\circ} \mathrm{C}$, sehingga dapat memperpanjang umur komponen dan meningkatkan performa turbin gas.

Sistem TBC modern terus dikembangkan tidak hanya berkaitan dengan kekuatan mekanik/resistan terhadap stress condition dan proses transfer panasnya tetapi juga perlindungan terhadap komponen mesin dari oksidasi dan korosi temperatur tinggi untuk menghindari kegagalan dini (spallation) selama siklus operasi [5]. Beberapa hal penting yang perlu diperhatikan dalam pengembangan sistem TBC, diantaranya adalah: pertama, lapisan TBC secara termal harus memiliki konduktivitas panas yang rendah. Hal ini diperlukan untuk memaksimalkan thermal drop sepanjang lapisan. Disamping itu, lapisan ini juga harus memiliki koefisien thermal ek- 


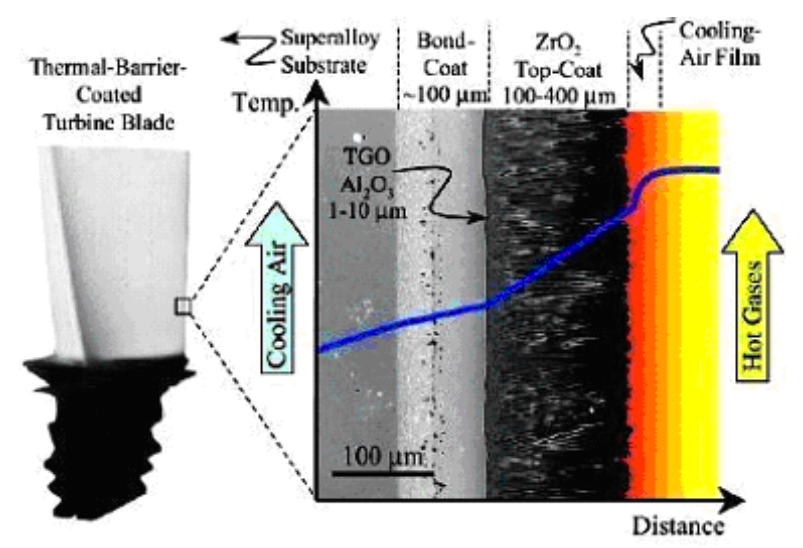

Gambar 1: Penampang Lintang Sistem TBC [4]

pansi yang berbeda dengan substrat yang dapat menjembatani perbedaan koefisien termal antara substrat dan TBC.

Kedua, lapisan yang tahan terhadap oksidasi dan korosi pada temperatur tinggi diperlukan untuk melindungi komponen turbin dari degradasi lingkungan. Lapisan ini harus tahan terhadap perubahan tegangan (stress), stabil selama pengoperasian (phase stability dan pore morphology stability) dan memiliki perekatan yang baik terhadap substrat untuk menghindari kegagalan dini pada sistem TBC. Oleh karena itu, sangatlah penting untuk menjaga kestabilan lapisan bondcoat (MCrAlY atau aluminide). Hal ini bergantung pada kandungan Al sebagai cadangan untuk pembentukan lapisan protektif alumina.

Kandungan Al dalam lapisan bondcoat akan berkurang seiring dengan pembentukan kembali lapisan alumina karena terkelupas (spallation) dan juga difusi-interdifusi Al ke dalam substrat yang dapat mengakibatkan turunnya sifat mekanik aloy substrat. Untuk mengatasi hal ini, berbagai usaha dilakukan diantaranya dengan menambahan unsur penguat batas butiran yang berfungsi untuk meningkatkan kekuatan dan ketahanan sistem TBC terhadap erosi, korosi, oksidasi dan keretakan (crack propagation) serta menyisipkan peperintang difusi (diffusion barrier) seperti : TiN, AlN, AlON, $\mathrm{ZrO}_{2}, \mathrm{Al}_{2} \mathrm{O}_{3}, \mathrm{Re}, \mathrm{W}$ dan lainnya [6]. Namun demikian, hingga saat ini belum didapatkan hasil yang maksimal, sehingga masih diperlukan penelitian untuk mendapatkan penguat batas butir dan perintang difusi yang tahan lama dan tetap stabil pada temperatur tinggi.

Pada makalah ini dibahas hasil penelitian awal pengembangan pelapisan TBC bondcoat $\mathrm{NiAl}$ pada paduan logam berbasis kobalt Co dengan penambahan unsur penguat batas butir menggunakan metoda yang terbilang murah dan sederhana yang sangat mungkin untuk diterapkan di Indonesia, yaitu gabungan metoda Electro-platting dan Pack-cementation. Pengujian sampel dilakukan dengan test oksidasi dan hasil pelapisan sebelum dan sesudah tes oksidasi dianalisa dengan SEM, XRD dan EPMA.

\section{METODOLOGI PENELITIAN}

Bahan yang digunakan sebagai substrat dalam penelitian ini adalah CoCrNi yaitu paduan logam berbasis kobalt Co yang banyak digunakan untuk aplikasi bahan mesin produksi energi hingga mencapai $1000^{\circ} \mathrm{C}$. Komposisi kimia bahan CoCrNi tercantum pada Table 1 .

TABEL I: Komposisi Kimia Bahan CoCrNi

\begin{tabular}{cccccccc}
\hline \hline & $\mathrm{Co}$ & $\mathrm{Cr}$ & $\mathrm{Ni}$ & $\mathrm{W}$ & $\mathrm{Si}$ & $\mathrm{Mn}$ & $\mathrm{Fe}$ \\
\hline wt\% & 54.39 & 29.80 & 10.52 & 2.70 & 1.20 & 0.61 & 0.60
\end{tabular}

Pada persiapan sampel, bahan dipotong berbentuk plat berukuran $(15 \times 10 \times 6) \mathrm{mm}^{3}$. Untuk keperluan proses electroplating pada sampel diberi lobang berdiameter $1,5 \mathrm{~mm}$ untuk mengikatkan kawat platina. Sebelum dilakukan proses pelapisan, sampel digosok dengan kertas ampelas nomor 150 dan dilanjutkan dengan pencucian dengan agitasi ultrasonic dalam larutan USC aceton. Adapun proses pembentukan lapisan alloy $\mathrm{Ni}-\mathrm{Al}$ phasa $\beta$ adalah sebagai berikut:

1. Ni strike plating 1-2 $\mu \mathrm{m}$, dimana Ni dilapiskan pada substrat dengan metoda electro-plating dengan menggunakan larutan $\mathrm{NiCl}_{2}$ dan $\mathrm{HCl}$ pada sumber arus 500 $\mathrm{mA} / \mathrm{cm}^{2}$ dan selama \pm 30 s pada temperatur ruang,

2. Dilanjutkan dengan pelapisan $\pm 38 \mu \mathrm{m}$ Ni dengan laru$\tan \mathrm{Ni}$-Watts,

3. Difusi Al dilakukan dengan metoda pack-cementation dengan media berupa serbuk aluminium Al yang dicampur dengan serbuk $\mathrm{Al}_{2} \mathrm{O}_{3}$ dengan perbandingan 1:3. Serbuk-serbuk tersebut di milling hingga rata dalam waktu \pm 1 jam dan ditambah $5 \%$ wt $\mathrm{NH}_{4} \mathrm{Cl}$. sampel kemudian dikubur dalam campuran serbuk tersebut dan diberi perlakuan panas pada temperatur $800{ }^{\circ} \mathrm{C}$ selama \pm 20 menit untuk membentuk lapisan $\mathrm{NiAl}$ yang berfungsi sebagai cadangan $\mathrm{Al}$.

Pada percobaan ini telah disiapkan 2 jenis sampel, yaitu sampel berupa bahan substrat tanpa pelapisan dan sampel yang dilapisi NiAl. Kemudian dilakukan tes oksidasi untuk sampel-sampel tersebut pada udara statik $1150^{\circ} \mathrm{C}$ selama 100 jam. Pada kedua sampel dilakukan penimbangan berat dan pengamatan elemen oksida secara periodik dengan XRD dan struktur mikro lapisan sebelum dan sesudah proses oksidasi diamati dengan EPMA untuk mendapatkan profil konsentrasi masing masing elemen.

\section{HASIL DAN DISKUSI}

Proses difusi lapisan aluminide pada substrat berdasarkan atas campuran antarlogam $\beta$-NiAl seperti ditunjukkan pada diagram phase Ni-Al (Gambar 2.a). Dari gambar tersebut ditunjukkan bahwa phase $\beta$-NiAl dapat tahan hingga temperatur 

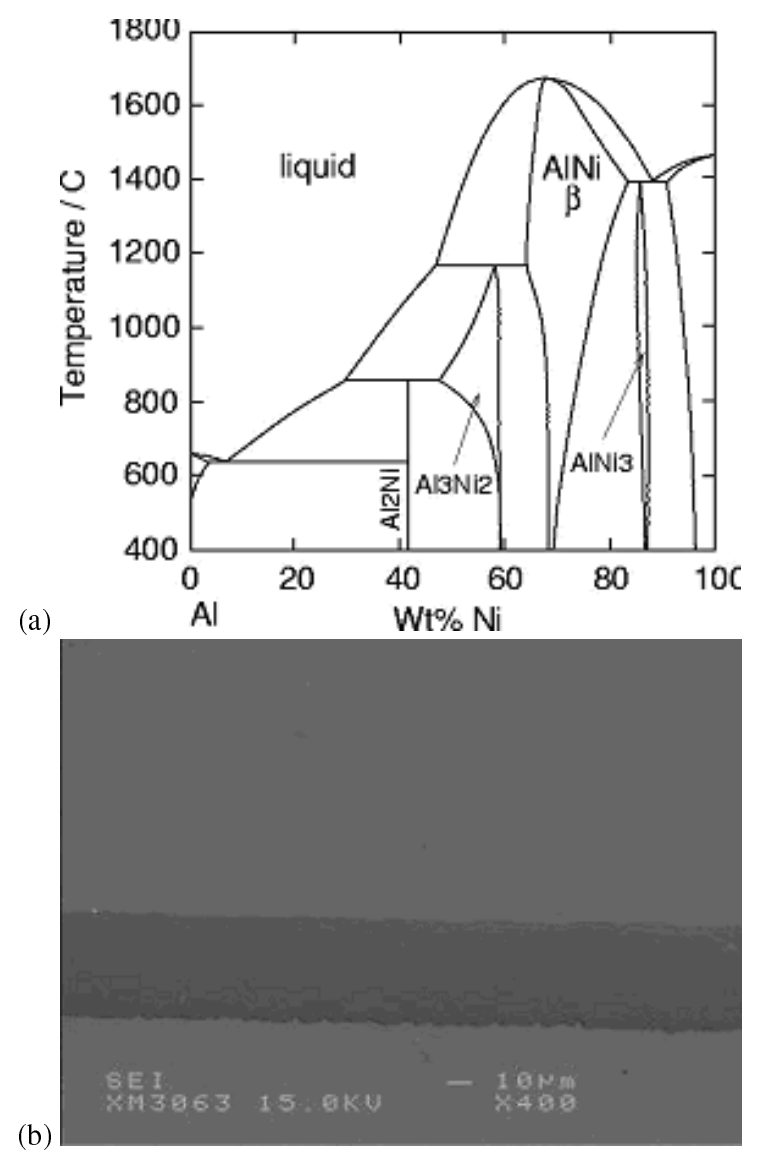

Gambar 2: (a) Diagram Phase Ni-Al, (b). Penampang Lintang sampel dengan Lapisan $\mathrm{NiAl}$

$\pm 1600^{\circ}$ C. Pada Gambar 2.b. ditunjukkan penampang lintang hasil pelapisan NiAl pada substrat berbasis kobalt Co dengan metoda pack-cementation.

Sampel-sampel tersebut (baik yang tidak dilapisi maupun yang dilapisi $\mathrm{NiAl}$ ) dilakukan tes oksidasi di dalam tungku bertemperatur $1150^{\circ} \mathrm{C}$ selama $\pm 100 \mathrm{jam}$. Perubahan berat sampel diamanti secara periodik sesuai dengan siklus temperatur oksidasi 9 jam, 25 jam, 49 jam dan 100 jam. Gambar 3.a. menunjukkan grafik hubungan perubahan berat sampel per $\mathrm{cm}^{2}$ terhadap waktu. Dari grafik tersebut terlihat bahwa pada 25 jam pertama, kedua sampel mengalami pertambahan berat akibat oksidasi. Namun pada waktu selanjutnya kerak oksida pada sampel yang tidak dilapisi NiAl mulai mengelupas/spallation (Gambar 3.b.) dan terus terjadi penurunan berat hingga mencapai lebih dari $3 \mathrm{mg} / \mathrm{cm}^{2}$. Sedangkan untuk sampel yang dilapisi dengan NiAl pada waktu yang sama, kerak oksida yang terbentuk belum mengelupas dan terjadi pertambahan berat $\pm 1,86 \mathrm{mg} / \mathrm{cm}^{2}$. Hal ini menunjukkan bahwa pelapisan NiAl pada substrat berbasis kobalt Co dapat mencegah terjadinya kegagalan dini dan dapat meningkatkan daya tahan substrat terhadap temperatur yang lebih tinggi.

Gambar 4. menunjukkan penampang lintang sampel tanpa lapisan NiAl sesudah tes oksidasi selama 100 jam pada temperatur $1150^{\circ} \mathrm{C}$. Dari gambar tersebut terlihat bahwa, proses oksidasi yang berlangsung di permukaan sampel menye-

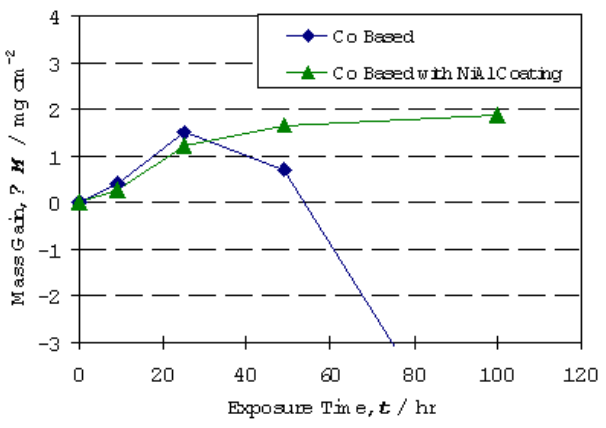

(a)

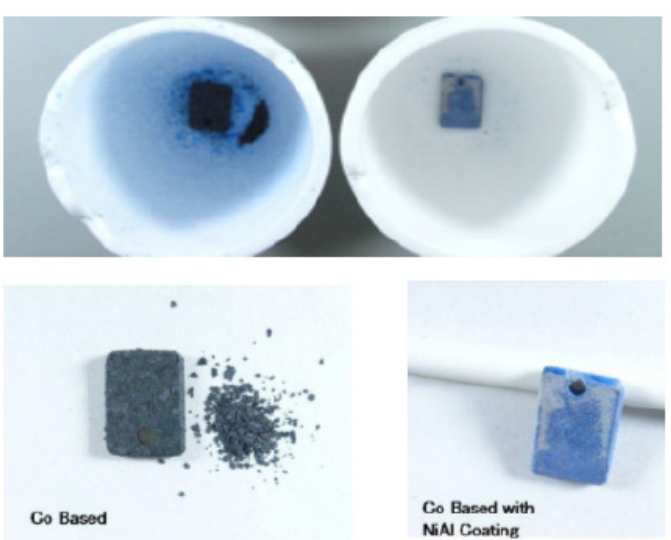

(b)

Gambar 3: (a). Pertambahan Berat sampel terhadap Waktu Oksidasi pada Temperatur $1150^{\circ} \mathrm{C}$, (b) sampel tanpa dan dengan Lapisan NiAl sesudah 100 jam Tes Oksidasi pada $1150^{\circ} \mathrm{C}$

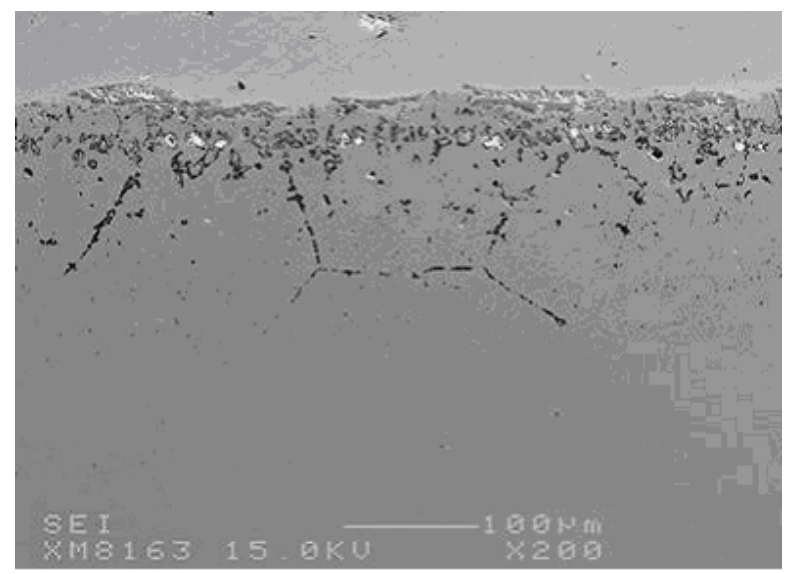

Gambar 4: Penampang Lintang sampel Tanpa Lapisan NiAl Sesudah 100 jam Tes Oksidasi pada $1150^{\circ} \mathrm{C}$

babkan terbentuknya pori-pori di sepanjang permukaan. Proses oksidasi ini sebagian menjalar ke bagian dalam sampel melalui batas-batas butir dan jika proses ini terus berlangsung dapat menyebabkan terjadinya spallation.

Gambar 5. menunjukkan struktur permukaan sampel yang dilapisi dengan $\mathrm{NiAl}$ setelah dilakukan tes oksidasi pada temperatur $1150^{\circ} \mathrm{C}$ selama 100 jam. Dari gambar tersebut dapat dilihat bahwa kerak oksida yang terbentuk selama proses oksidasi tidaklah merata. Untuk mempelajari pengaruh lapisan 


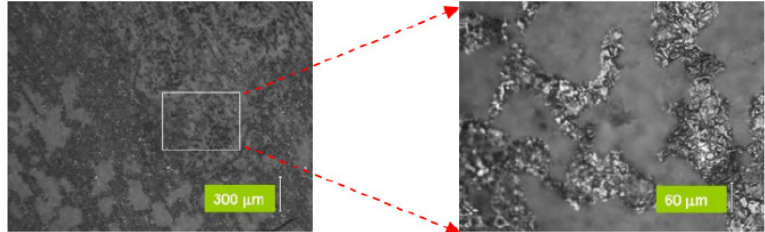

Gambar 5: Stuktur Permukaan sampel dengan Lapisan NiAl sesudah 100 jam Tes Oksidasi pada $1150^{\circ} \mathrm{C}$

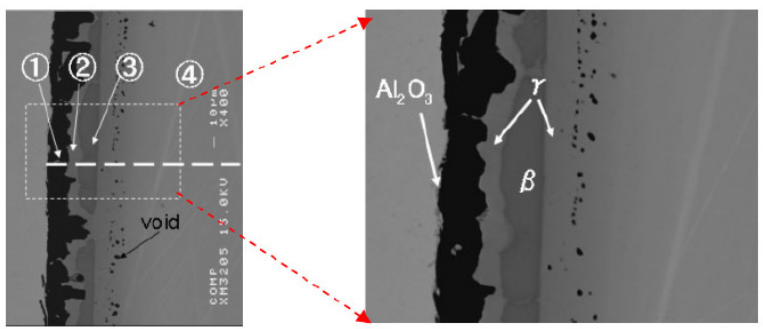

Gambar 6: Penampang Lintang sampel dengan Lapisan NiAl Sesudah 100 jam Tes Oksidasi pada $1150^{\circ} \mathrm{C}$

NiAl pada sampel barbasis kobalt Co, dilakukan analisa struktur mikro dan profil konsentrasi masing-masing elemen kimia sesudah tes oksidasi.

Gambar 6. dan 7. merupakan gambar penampang lintang dan profil konsentrasi elemen kimia dari sampel dengan lapisan NiAl setelah dilakukan tes oksidasi pada temperatur $1150^{\circ} \mathrm{C}$ selama 100 jam. Dari profil konsentrasi tersebut dapat diketahui bahwa kerak oksida yang terbentuk (poin 1) berupa $\alpha-\mathrm{Al}_{2} \mathrm{O}_{3}$, dan poin 2, 3 dan 4 masing-masing adalah $\gamma$-NiAl, $\beta$-NiAl dan substrat. Dari Gambar 6 juga dapat dilihat bahwa timbul void-void di antara permukaan substrat dan lapisan NiAl. Hal ini terjadi karena pada waktu sampel dipanaskan pada temperatur $1150^{\circ} \mathrm{C}$, ada $\mathrm{Al}$ dari lapisan NiAl yang berdifusi ke permukaan sampel membentuk kerak oksida $\alpha-\mathrm{Al}_{2} \mathrm{O}_{3}$, juga terjadinya interdifusi antara $\mathrm{Al}$ dari lapisan $\mathrm{NiAl}$ dan $\mathrm{Co}$ yang berasal dari substrat. Laju interdifusi Al berjalan lebih lambat dibandingkan laju interdifusi kobalt $\mathrm{Co}$, untuk mengisi ruang kosong yang ditinggalkan Co. Dengan demikian, timbullah void-void diantara substrat dan lapisan $\mathrm{NiAl}$, apabila proses ini terus berlangsung dapat menyebabkan terjadinya spallation.

Hasil penelitian di atas perlu dilakukan optimasi pelapisan $\mathrm{NiAl}$ pada sampel berbasis kobalt Co. Baik dalam hal struktur morfologinya maupun menghilangkan void-void yang timbul selama tes oksidasi karena hal tersebut dapat memperpendek umur pemakaiannya.

\section{SIMPULAN}

Hasil tes oksidasi yang dilakukan pada lapisan termal barrier coating (TBC) NiAl pada paduan logam berbasis kobalt yang dihasilkan dari gabungan metoda electro-plating $\mathrm{Ni}$ dan $\mathrm{Ni}$-Watt serta pack-cementation $\mathrm{Al}$ dengan media serbuk alumina di dalam udara statik bertemperatur $1150^{\circ} \mathrm{C}$ selama \pm 100 jam, menunjukkan bahwa :

1. Pelapisan NiAl dapat meningkatkan daya tahan sampel untuk aplikasi temperatur yang lebih tinggi.

2. Morfologi permukaan kerak oksida $\alpha-\mathrm{Al}_{2} \mathrm{O}_{3}$ yang terbentuk memiliki ketebalan yang tidak merata

3. Timbulnya void-void pada sampel, yang mana hal ini tidak diinginkan karena apabila hal ini terus berlangsung dapat menyebabkan terjadinya spallation.

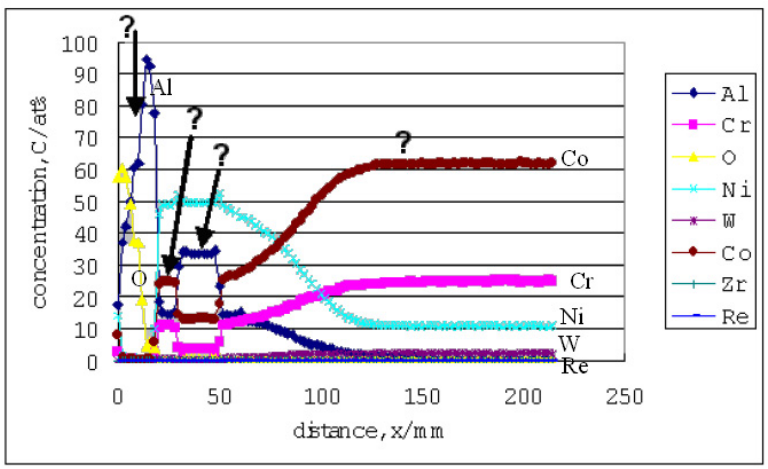

Gambar 7: Profil Konsentrasi Elemen Kimia sampel dengan Lapisan $\mathrm{NiAl}$ Sesudah 100 jam Tes Oksidasi pada $1150^{\circ} \mathrm{C}$
[1] Seals R. D. dkk., Thermal barrier coating for alloy system, United States Patent, No. 6,071,628,(2000).

[2] Murphy K. S., Thermal barrier coating system with intermediate phase bond coat, United States Patent, No. 5,716,720, (1998).

[3] Xie Liangde. Dkk., Surface and Coating Technology, Elsevier., 177-178, 103-107,(2004).

[4] Nitin P. Padture, dkk.,'Thermal barrier coating for gas-turbin engine application', 'Advanced thermal barrier coating for industrial gas turbin engines', Available : [http://www.sciencemag. org] (tanggal akses : 5 Maret 2007)(2002, 2003).

[5] Stiger M.J., dkk., 'Thermal barrier coatings for the 21 st century', Department of Materials Science and Engineering, University of Pittsburgh', Available : [http://www.answers.com/thermal barrier coating/] (tanggal akses : 3 Maret 2007), (2000).

[6] Thosin K. A. Zaini, 'Diffusion barrier coating dan peranannya dalam sistem pelindung termal pada material temperature tinggi. (Proses publikasi), (2006) 